\title{
Demographic correlates of DSM-IV major depressive disorder among older African Americans, Black Caribbeans, and non-Hispanic Whites: results from the National Survey of American Life
}

\author{
María P. Aranda ${ }^{1}$, David H. Chae ${ }^{2}$, Karen D. Lincoln ${ }^{1}$, Robert Joseph Taylor ${ }^{3}$, Amanda Toler Woodward ${ }^{4}$ \\ and Linda M. Chatters ${ }^{3}$ \\ ${ }^{1}$ Social Work, University of Southern California, Los Angeles, California, United States, 90089 \\ ${ }^{2}$ Behavioral Sciences and Health Education, Rollins School of Public Health, Emory University, Atlanta, Georgia, United States \\ ${ }^{3}$ Social Work, University of Michigan, Ann Arbor, Michigan, United States \\ ${ }^{4}$ School of Social Work, Michigan State University, East Lansing, Michigan, United States, 48824 \\ Correspondence to: María P. Aranda, PhD, E-mail: aranda@usc.edu
}

\begin{abstract}
Objectives: To examine the demographic correlates of lifetime and 12-month prevalence of major depressive disorder (MDD) among older African Americans, Black Caribbeans, and non-Hispanic Whites. Methods: Data are from adults aged 55 years and older $(n=1439)$ recruited to the National Survey of American Life (NSAL; 2001-2003). The Diagnostic and Statistical Manual Version IV World Mental Health Composite International Diagnostic Interview was used to assess the 12-month and lifetime MDD. Weighted logistic regression was used to model demographic correlates of MDD.

Results: The population prevalence of lifetime and 12-month MDD were $11.2 \%$ and $4.1 \%$, respectively. Bivariate analyses revealed that younger respondents and those with greater disability had a higher prevalence of both lifetime and 12-month MDD compared with those who were older and who had lower disability. Multivariable logistic regressions controlling for demographic characteristics revealed that non-Hispanic Whites had the greatest odds of lifetime $\mathrm{MDD}(\mathrm{OR}=2.27,95 \% \mathrm{CI}=1.32,3.93)$. Women had significantly greater odds of lifetime MDD compared with men $(\mathrm{OR}=2.49,95 \% \mathrm{CI}=1.14,5.41)$; there were no gender differences in 12-month MDD. Other significant predictors of MDD were marital status and region of residence.

Conclusions: The distribution, correlates, and nature of associations with MDD vary as a function of whether we examined lifetime vs. 12-month MDD. Future work should account for within group differences among older adults with depression. Understanding MDD correlates and the nature of intergroup diversity can inform the identification of particularly vulnerable subgroups as well as appropriate treatment approaches. Copyright (C) 2011 John Wiley \& Sons, Ltd.
\end{abstract}

Key words: depression; Caribbean Blacks; race; ethnicity gender; disability; marital status

History: Received 6 April 2011; Accepted 22 August 2011; Published online 28 October 2011 in Wiley Online Library (wileyonlinelibrary.com).

DOI: 10.1002 /gps.2805

\section{Introduction}

Major depressive disorder (MDD) is highly prevalent (McKenna et al., 2005; Mathers \& Loncar, 2006) and a significant public health concern, having individual, family, and societal tolls (Katon et al., 2003; Kessler et al., 2003; Papakostas et al., 2004; Hasin et al., 2005). Although a serious issue in non-White, as well as older adult populations, relatively few studies have been conducted on these populations; and only recently have studies been conducted on psychiatric disorders experienced by minority elderly in the USA 
(Ford et al., 2007; Jimenez et al., 2010). This study seeks to contribute to this body of knowledge by examining the prevalence and correlates of MDD among a representative sample of older African Americans, Black Caribbean, and non-Hispanic Whites.

Although MDD is common, it is less frequent in older adults compared with younger adults (Brown et al., 1995; Ford et al., 2007; Scott et al., 2008; Gum et al., 2009). The prevalence is elevated in women compared with men across all age groups (Piccinelli \& Wilkinson, 2000), and is associated with significant medical and functional comorbidity, physiological abnormalities, and even death (Blazer, 2002, 2003; Alexopoulos, 2005; Fiske et al., 2009). As seen in younger people, the course of depression in older populations is marked by exacerbations, remissions, and chronicity (Blazer, 2002, 2003). For example, $60 \%$ of older adults who recover from a major depressive episode have a subsequent episode, and up to $40 \%$ of depressed older adults can experience relapse and chronicity (Salzman et al., 2000). It is widely known that geriatric depression differs to some degree from depression in younger cohorts in terms of symptom presentation such that older persons frequently present with somatic symptomatology, psychomotor retardation, as well as higher suicide rates, and cognitive decline (Salzman et al., 2000; Blazer, 2002, 2003; Fiske et al., 2009).

Studies comparing treatment response in older versus middle-aged depressed patients have found that treatment differences in remission rates were not clinically significant between older and younger patients (Mitchell \& Subramaniam, 2005; Cohen et al., 2006; Ell et al., 2010), thus underscoring older adults' favorable response to depression treatment. Despite evidence that depression is treatable in older adults, comorbid medical and neurological illnesses often co-occur with late-life depression. Comorbidity can negatively influence the diagnosis and initiation of depression treatment (Nutting et al., 2000; Rost et al., 2000) as well as treatment response (Mitchell \& Subramaniam, 2005; Kiosses et al., 2011). Unfortunately, depression under-treatment or nonadherence to treatment can be found among geriatric patients as well as among racial and ethnic minorities because of well documented patient, provider, and organizational barriers (Areán \& Unützer, 2003; Ell, 2006; Areán et al., 2007; Alegria et al., 2008; González et al., 2010a, 2010b). Ascertaining subgroups with heightened vulnerability for MDD can increase our understanding of the factors underlying disparities in access-and response to-quality depression treatments.
Although lifetime estimates of MDD among adults, including older adults, have varied across epidemiological studies, ranging from 3.0\% to 19.0\% (Breslau et al., 2006; Hasin et al., 2005; Kessler et al., 2003; Ford et al., Gum et al., 2009; Jimenez et al., 2010; Blazer et al., 1994; Eaton et al., 1984; Robins, 1991; Takeuchi et al., 1998; Weissman et al., 1991; Areán et al., 2005), they have typically found that non-Hispanic Whites have the highest prevalence compared with other US racial/ethnic minority groups, with a lower prevalence found among racial/ethnic minorities (Hasin et al., 2005; Gum et al., 2009). Research from the National Survey of American Life (NSAL) by Willams and colleagues (2007) reported similar prevalence estimates of MDD for African Americans and Black Caribbeans, although among those over 60 years of age, African Americans had a slightly lower prevalence (Williams et al., 2007). Prevalence estimates for both Black groups were nevertheless lower compared with non-Hispanic Whites. They also found that relative to non-Hispanic Whites, African Americans and Black Caribbeans were more likely to rate their MDD as severe or very severe (Williams et al., 2007). In addition, less than half of the African American adults (45.0\%) and fewer than a quarter $(24.3 \%)$ of the Black Caribbeans adults who met the criteria for MDD received any form of treatment.

Until recently, research on psychiatric disorders among older adults based on nationally representative samples has been lacking. In a seminal investigation of psychiatric disorders among older adults, Gum and her associates (Gum et al., 2009) examined the correlates of mood and anxiety disorders among adults 65 years and older. They found age, gender, and racial differences in lifetime mood disorders: women, adults 65-69, and African Americans were less likely to have had a lifetime mood disorder (Gum et al., 2009).

There is a small but emerging body of research on ethnic and racial differences in the prevalence and correlates of psychiatric disorders among older adults. Using NSAL data, Ford and her associates (Ford et al., 2007) presented the first national prevalence estimates of Diagnostic and Statistical Manual Version IV (DSM-IV) anxiety, mood, and substance abuse disorders among older African Americans. Twenty-three percent of African Americans aged 55 years and older met diagnostic criteria for one lifetime disorder; 8.5\% met criteria for a 12-month disorder (with alcohol abuse, PTSD, and major depression most prevalent), and prevalence declined with age (Ford et al., 2007). Jimenez et al. (2010) used the Collaborative Psychiatric Epidemiology Surveys to investigate nativity, number of years in the US, and language differences in psychiatric 
disorders across several racial and ethnic subgroups 60 years and older. Contrary to their expectations, the prevalence of disorders was not higher for older adults born in the USA as compared with immigrants (Jimenez et al., 2010). Similarly, González et al. (2010a) found that the prevalence of MDD was greater for USA versus foreign-born respondents except for foreignborn respondents aged 65 years and older. Both studies (González et al., 2010a; Jimenez et al., 2010) found that the protective effect of immigrant status on psychiatric disorders was not evident for older racial and ethnic minorities. Yet, neither study investigated associations specifically between socioeconomic or other demographic factors in relation to MDD.

Our study aims to complement this emerging body of research by modeling a wide range of potential demographic correlates of DSM-IV-derived MDD among a nationally representative sample of African American, Black Caribbeans, and non-Hispanic White older adults. We hypothesize that prevalence of MDD would be highest among non-Hispanic Whites compared with African Americans and Black Caribbeans, and lowest among African Americans (Williams et al., 2007; Gum et al., 2009; Lincoln et al., 2010). In line with previous research, we also expect to find elevated MDD prevalence among respondents who are women (Williams et al., 2007; Gum et al., 2009), younger (Ford et al., 2007; Gum et al., 2009), are not married (Gum et al., 2009; Williams et al., 2007), reside outside of the southern region of the USA (Ford et al. 2007) and report greater disability (Liao et al., 1999; Alexopoulos, 2005; Chapman et al., 2005).

\section{Methods}

\section{Setting and study design}

The NSAL is the most comprehensive study of mental disorders of non-institutionalized adult Americans of African descent ever conducted. Fieldwork for the study was completed at the University of Michigan by the Institute for Social Research's Survey Research Center, in cooperation with the Program for Research on Black Americans (Jackson et al., 2004). Data were collected from 2001 to 2003. This study was approved by the University of Michigan Institutional Review Board.

\section{Sample and procedures}

A total of 6,082 interviews were conducted with persons aged 18 years or older, including 3,570 African
Americans, 891 non-Hispanic Whites, and 1,621 Blacks of Caribbean descent. With a $72.3 \%$ response rate, $14 \%$ of interviews were completed over the phone and $86 \%$ were administered face-to-face in respondents' homes. Final response rates for the NSAL two-phase sample designs were computed using the American Association of Public Opinion Research (AAPOR) guidelines.

The African American sample is the core sample of the NSAL and was recruited from 64 primary sampling units (PSUs). The African American sample is a nationally representative sample of households located in the 48 coterminous states with at least one Black adult 18 years of age or over who did not identify ancestral ties in the Caribbean. Both the African American sample and non-Hispanic White comparison sample were selected exclusively from these targeted geographic segments in proportion to the African American population.

The Black Caribbean sample was selected from two area probability sampling frames: the core NSAL sample and an area probability sample of housing units from geographic areas with a relatively high density of persons of Caribbean descent (more than 10\% of the population). Of the total Black Caribbean respondents $(n=1,621), 265$ were selected from the households in the core sample, whereas 1,356 were selected from housing units from high-density Caribbean areas.

Analyses were restricted to 1439 participants aged 55 years and older.

\section{Measures}

Major depressive disorder. Presence of lifetime and 12-month MDD was assessed using the MDD battery of the World Mental Health Survey Initiative version of the World Health Organization Composite International Diagnostic Interview (WMH-CIDI). The WMH-CIDI is a fully structured instrument designed to detect psychiatric disorders using DSM-IV criteria, which include affective, cognitive, and somatic symptoms of depression (i.e., depressed affect, difficulty concentrating, and changes in appetite, weight, and sleep). Validation studies of the WMH-CIDI have found high levels of concordance with blind clinical appraisals.

Demographic and socioeconomic correlates. We included self-reported measures of age, gender, race/ethnicity, marital status, education, poverty ratio, and disability. Marital status was categorized into married or partnered, widowed, and "other" (never married, separated, or divorced). Poverty ratio was calculated as household income in relation to the poverty threshold 
based on household composition. Region was dichotomized into those living in the South versus those living in other US regions.

A modified version of the World Health Organization Disability Assessment Schedule (WHO-DAS) measured past 30-day disability across seven domains: cognitive; days out of role; productivity; self-care; mobility; social life; and family burden. Items assessed the number of days of impairment in each domain weighted by selfassessed difficulty in performing activities. Scores in each of the seven domains were transformed to range from zero (no impairment) to one (complete impairment in at least two domains) and totaled for a disability summary score $(\alpha=0.78)$.

\section{Statistical analysis}

Our descriptive analyses were aimed at providing the distribution of demographic and socioeconomic correlates in the overall sample, and by presence of both lifetime and 12-month MDD. For bivariate analyses of continuous variables (age, education, poverty ratio, and disability score), we created categories using a priori cut-points. To test for significant differences in the prevalence of lifetime and 12-month MDD, we used Wald chi-square tests.

We conducted multivariate logistic regressions to predict both lifetime and 12-month MDD. Age, education, poverty ratio, and disability score were treated as continuous variables. We used the Wald F-statistic to determine the overall significance of the independent variables. We excluded 71 participants with missing MDD data, and an additional 32 participants with missing covariate data, leaving a total sample size of 1336 participants used in the multivariate analyses. All analyses were weighted and took into account complex survey design characteristics using SAScallable SUDAAN Version 10.0.0. The NSAL weights were selected to correct for disproportionate sampling, non-response, and to provide representation across various demographic characteristics of the US population residing in the 48 coterminous states.

\section{Results}

Characteristics of the NSAL sample by presence of lifetime and 12-month DSM-IV MDD are presented in Table 1. Lifetime and 12-month estimates of MDD were $11.2 \%$ and $4.1 \%$, respectively. Wald chi-square tests adjusting for clustering revealed significant bivariate associations predicting lifetime MDD prevalence by the following: age $\left(\chi^{2}=4.29,1 d f, p<0.05\right)$, with younger age associated with a greater prevalence; marital status $\left(\chi^{2}=6.56,2 d f, p<.01\right)$, with those who were never married, separated, or divorced ("other" category) having a higher prevalence; and disability $\left(\chi^{2}=5.34,3\right.$ $d f, p<0.01$ ), with greater disability associated with a higher prevalence. In predicting 12-month MDD prevalence, we did not find evidence for significant differences by marital status but continued to find associations with younger age $\left(\chi^{2}=3.82,1 d f, p<0.05\right)$ and higher disability $\left(\chi^{2}=4.83,3 d f, p<0.01\right)$.

Results from weighted multivariate logistic regression analyses (Table 2) support the initial descriptive findings presented above regarding the association between demographic and socioeconomic factors and MDD. In the model predicting lifetime MDD, significant associations were found with race/ethnicity, gender, marital status, and disability. Specifically, nonHispanic Whites had significantly greater odds of having lifetime MDD compared with African Americans $(\mathrm{OR}=2.27,95 \% \mathrm{CI}=1.32,3.93)$. In addition, women had approximately 2.5 times the odds of lifetime MDD compared with men $(\mathrm{OR}=2.49,95 \% \mathrm{CI}=1.15$, 5.41). Marital status was also a statistically significant predictor of lifetime MDD, with those who were widowed having the lowest odds, and those of "other" marital status (never married, separated, divorced) having the highest odds. Disability was a significant predictor, with higher levels of disability associated with significantly greater odds of both lifetime $(O R=2.10$, $95 \% \mathrm{CI}=1.37,3.23)$ and 12 -month $\mathrm{MDD}(\mathrm{OR}=3.12$, $95 \% \mathrm{CI}=2.13,4.56$ ).

Marital status was also a significant predictor of 12-month MDD, but contrary to results of lifetime MDD, those who were never married, separated, or divorced ("other") had significantly lower odds of 12-month MDD compared with those who were married or partnered. In addition, participants living in non-South regions of the US had significantly greater odds of 12-month MDD compared with those living in the South. Race/ethnicity was a significant correlate of lifetime MDD, but not for 12-month $\operatorname{MDD}(F=2.68,2 d f, p=0.08)$.

\section{Discussion}

Our findings revealed that the distribution, correlates, and the nature of associations with MDD vary as a function of whether we examined lifetime versus 12-month MDD. The odds of lifetime MDD were significantly higher among non-Hispanic Whites, women and respondents with high disability. Twelve-month MDD rates were significantly higher among disabled 
Table 1 Descriptive characteristics of participants 55 years of age and older $(n=1439)$ by presence of lifetime and 12-month major depression in the National Survey of American Life (NSAL; 2001-2003)

\begin{tabular}{|c|c|c|c|c|c|}
\hline & \multicolumn{2}{|c|}{ Lifetime Major Depression, $n(\%)$} & \multicolumn{2}{|c|}{ 12-Month Major Depression, $n(\%)$} & \multirow{2}{*}{$\begin{array}{l}\text { Total } \\
n(\%)\end{array}$} \\
\hline & No & Yes & No & Yes & \\
\hline \multicolumn{6}{|l|}{ Lifetime MDD } \\
\hline No & & & & & $1251(88.8)$ \\
\hline Yes & & & & & 117 (11.2) \\
\hline \multicolumn{6}{|l|}{ 12-Month MDD } \\
\hline No & & & & & 1319 (95.9) \\
\hline Yes & & & & & $49(4.1)$ \\
\hline \multicolumn{6}{|l|}{$\mathrm{Age}^{*, \dagger}$} \\
\hline 55-64 years & $567(85.0)$ & $74(15.0)$ & 607 (94.9) & $34(5.1)$ & $669(46.7)$ \\
\hline $65-74$ years & $446(91.3)$ & $33(8.7)$ & $468(97.9)$ & $11(2.1)$ & 500 (33.9) \\
\hline \multicolumn{6}{|l|}{ Gender } \\
\hline Men & $481(92.5)$ & $34(7.5)$ & $497(95.1)$ & $18(4.9)$ & $543(44.6)$ \\
\hline Women & $770(85.9)$ & $83(14.2)$ & $822(96.5)$ & $31(3.5)$ & $896(55.4)$ \\
\hline \multicolumn{6}{|l|}{ Race/Ethnicity } \\
\hline African American & 729 (93.3) & $57(6.7)$ & $761(97.1)$ & $25(2.9)$ & $837(40.7)$ \\
\hline Black Caribbean & $276(88.5)$ & 19 (11.5) & $282(89.3)$ & $13(10.7)$ & $304(2.7)$ \\
\hline White & $246(85.7)$ & $41(14.3)$ & $276(95.3)$ & $11(4.7)$ & $298(56.5)$ \\
\hline \multicolumn{6}{|l|}{ Education } \\
\hline$<12$ years & 458 (93.2) & $39(6.8)$ & $476(96.0)$ & $21(4.0)$ & $521(30.4)$ \\
\hline 12 years & $435(88.2)$ & 39 (11.8) & $423(97.5)$ & $12(2.5)$ & $460(33.1)$ \\
\hline $\begin{array}{l}\geq 13 \text { years } \\
\text { Poverty Ratio }\end{array}$ & \multicolumn{4}{|c|}{ Poverty Ratio } & $458(36.4)$ \\
\hline Poor: $<1.00$ & $267(89.3)$ & $28(10.7)$ & $280(95.1)$ & $15(5.0)$ & 309 (14.5) \\
\hline Near-Poor: 1.00-1.99 & 347 (89.9) & $33(10.1)$ & $364(94.5)$ & $16(5.5)$ & $403(24.1)$ \\
\hline \multirow{2}{*}{\multicolumn{6}{|c|}{ Marital Status ${ }^{\star \star}$}} \\
\hline & & & & & \\
\hline Married/Partnered & $444(88.0)$ & $36(12.1)$ & 461 (94.4) & $19(5.6)$ & $494(46.0)$ \\
\hline Widowed & 405 (94.1) & $25(5.9)$ & $419(97.9)$ & $11(2.1)$ & $450(26.0)$ \\
\hline Other & $400(85.4)$ & $56(14.6)$ & 437 (96.4) & 19 (3.6) & $479(28.0)$ \\
\hline \multicolumn{6}{|l|}{ Region } \\
\hline South & $723(90.5)$ & $57(9.5)$ & $758(97.4)$ & $22(2.6)$ & $820(56.0)$ \\
\hline Non-South & $528(86.8)$ & 60 (13.2) & $561(94.0)$ & $27(6.0)$ & $619(44.0)$ \\
\hline \multicolumn{6}{|l|}{ Disability Score ${ }^{\star *,+\dagger}$} \\
\hline 0 & $770(93.4)$ & $35(6.6)$ & 798 (99.5) & $7(0.5)$ & 805 (55.9) \\
\hline $0.01-0.99$ & $324(87.0)$ & 47 (13.0) & 354 (95.9) & $17(4.1)$ & $372(30.3)$ \\
\hline $1.00-1.99$ & $82(81.9)$ & $13(18.1)$ & 85 (83.1) & 10 (16.9) & $96(9.6)$ \\
\hline$\geq 2.00$ & $49(68.5)$ & 18 (31.5) & 55 (79.0) & $12(21.0)$ & $67(4.2)$ \\
\hline
\end{tabular}

Note: Row sum may not equal total because of missing data. Percents by major depression represent prevalence of the outcome. Percents in total column represent distribution of participant characteristics.

Lifetime MDD: ${ }^{*} p<0.05 ;{ }^{* *} p<0.01 ;{ }^{* * *} p<0.001$.

12-Month MDD: ${ }^{\dagger} p<0.05 ;{ }^{\dagger+} p<0.01 ;{ }^{+\dagger} p<0.001$.

respondents and lower among Southerners and respondents who were never married, separated and divorced.

Although the bivariate analysis did not reveal any racial/ethnic differences in overall MDD prevalence rates, in our multivariate analysis non-Hispanic Whites had greater odds of lifetime MDD than African Americans. The lower MDD prevalence among African Americans is consistent with previous epidemiologic studies (Breslau et al., 2006; Kessler et al., 2003; Jimenez et al., 2010; Williams et al., 2007). Several possible explanations exist for the lower prevalence of MDD among African Americans. First, prior evidence suggests that African Americans may express psychological distress differently than non-Hispanic Whites. Namely, symptom presentation is less focused on mood disturbances and more focused on somatic complaints (Brown et al., 1996). Second, there may be a higher prevalence of protective factors, such as religion (Taylor et al., 2007) and familial support (Chatters et al., 1985; Woodward et al., 2008) that buffer against poor mental health. For example, older African Americans have higher levels of religious participation than non-Hispanic Whites (Levin et al., 1994; Taylor et al., 2007), and among African Americans, religious participation has been found to be inversely associated with mood disorders (Chatters et al., 2008). Third, Jackson and colleagues (Jackson \& Knight, 2006; 
Table 2 Weighted logistic regressions predicting lifetime and 12-month major depression among participants $(n=1336)$ in the National Survey of American Life (NSAL; 2001-2003)

Lifetime Major Depression OR $(95 \% \mathrm{Cl})$

$\begin{array}{lc}\text { Race/Ethnicity } & \\ \text { Caribbean versus African American } & 1.83(0.57,5.87) \\ \text { White versus African American } & 2.27(1.32,3.93) \\ & F=4.74,2 d f, p=0.02 \\ \text { Age } & 0.96(0.91,1.01) \\ & F=3.05,1 d f, p=0.09 \\ \text { Gender: Women versus Men } & 2.49(1.15,5.41) \\ & F=5.53,1 d f, p=0.02 \\ \text { Years of Education } & 1.08(0.96,1.20) \\ \text { Poverty Ratio } & F=1.08,1 d f, p=0.19 \\ & 0.98(0.86,1.11) \\ \text { Marital Status } & F=0.98,1 d f, p=0.73 \\ \text { Widowed versus Married/Partnered } & 0.58(0.25,1.34) \\ \text { Other versus Married/Partnered } & 1.25(0.57,2.75) \\ & F=4.61,2 d f, p=0.01 \\ \text { Region: Non-South versus South } & 1.44(0.63,3.27) \\ \text { Disability Score } & F=0.77,1 d f, p=0.38 \\ & 2.10(1.37,3.23) \\ & F=12.05,1 d f, p<0.001\end{array}$

12-Month Major Depression OR (95\% Cl)

$$
\begin{gathered}
4.05(1.11,14.84) \\
1.58(0.63,3.97) \\
F=2.68,2 d f, p=0.08 \\
0.98(0.91,1.05) \\
F=0.33,1 d f, p=0.57 \\
1.00(0.47,2.12) \\
F=0.00,1 d f, p=0.99 \\
1.14(0.94,1.39) \\
F=1.76,1 d f, p=0.19 \\
0.75(0.51,1.11) \\
F=2.14,1 d f, p=0.15 \\
0.30(0.06,1.65) \\
0.28(0.10,0.76) \\
F=3.24,2 d f, p=0.045 \\
3.82(1.18,12.37) \\
F=5.17,1 d f, p=0.03 \\
3.12(2.13,4.56) \\
F=35.44,1 d f, p<0.001
\end{gathered}
$$

Jackson et al. 2010; Mezuk et al., 2010) posit that lower rates of mental disorders among African Americans may come at the expense of higher rates of physical disorders. To cope with daily life stressors (e.g., lower socio-economic status, racial discrimination, residing in high crime neighborhoods), African Americans may engage in unhealthy behaviors (e.g., smoking, alcohol use, eating of comfort foods, and overeating). These unhealthy behaviors may reduce the likelihood of having a mental disorder but increase the likelihood of developing chronic physical illnesses in late life (e.g., diabetes, cardiovascular disease). Lastly, research on racial socialization indicates that many African American children are socialized to develop high levels of tolerance for unfair acts (e.g., Thornton et al., 1990). This type of socialization may be a protective psychological resource against the development of depression and other psychiatric disorders.

We also found that respondents who were never married, separated or divorced, had lower odds of 12-month MDD compared with those married/partnered. This finding is inconsistent with previous research indicating that married adults have lower rates of depression than their unmarried counterparts (Williams et al., 1992) and that married older adults have a lower prevalence of lifetime mood disorders (Gum et al., 2009). Although the general literature on marriage and mental health indicates that those with psychiatric disorders have substantially high rates of early marriage and subsequent divorce (Forthofer et al., 1996; Kessler et al., 1998), our findings suggest that among older adults, this may not necessarily be the case. Older adults who have been in stable, long-term marriages may be less likely to divorce because of a spouse's depression. This may particularly be the case for late onset depression or depression that accompanies declining health or disability.

Greater disability was consistently associated with higher MDD prevalence and odds of MDD. Findings also revealed that respondents with greater disability-that is, those with complete impairment in a least two domains-had the highest prevalence of MDD than any other subgroup in the sample (up to 31.5\%). These results are consistent with a previous work highlighting the strong link between disability and depression in older adults (Liao et al., 1999; Alexopoulos, 2005; Chapman et al., 2005). This is especially salient to our sample given that prior work has found that African Americans and Black Caribbeans with MDD not only report higher levels of impairment but are more persistently ill than their White counterparts, thus exhibiting a heightened burden of disease (Brown et al., 1996; Williams et al., 2007). Etiologic mechanisms implicated in the relationship between disability and MDD span individual factors (e.g., poor self-care strategies, heightened sensitivity to acute and chronic stress, biological pathways such as increased proinflammatory and cortisone activity) and external factors (inadequate medical care, stigma/discrimination, environmental stress exposure) (Alexopoulos, 2005; Fiske et al., 2009).

Gender was significantly associated with lifetime MDD, with women having greater odds of lifetime MDD than men. This finding is consistent with those 
of previous studies reporting higher prevalence of depression for women than men beginning as early as 15 years of age and continuing into late adulthood (Piccinelli and Wilkinson, 2000). Compared with their male counterparts, women face a combination of individual and social factors that place them at elevated risk for depression including differential expressions of psychological distress, multiple role responsibilities, and gender-related oppression (Piccinelli \& Wilkinson, 2000). However, we found no significant relationships between gender and 12-month MDD.

Respondents living in non-South regions had greater odds of 12-month MD compared with those living in the South. Although poverty rates are highest in the South, living in the South has been found to be a protective factor for mood disorders among older African Americans (Ford et al., 2007). The protective aspects of Southern residence may be due to several factors, including higher levels of religious participation among Southerners (Taylor et al., 2007), as well as larger social support networks that can be accessed for mental health problems as well as health issues more broadly (Chatters et al., 1985).

There are several caveats to our findings. As with any cross-sectional analyses, causal inferences are problematic and longitudinal data are preferred. For example, without prospective data, it is difficult to ascertain the causal order of our variables as predisposing factors or as consequences of MDD. Because our sample did not include homeless and institutionalized individuals, the findings are not generalizable to these subgroups. Item nonresponse, which is a common issue in survey interviewing, may have led to underreporting of MDD symptoms because of the sensitive nature of the items. Our prevalence estimates by age, particularly for lifetime MDD, may also have been a methodological artifact of recall bias, which is accentuated in older populations (Simon et al., 1995). Analyses conducted on 12-month MDD should also be interpreted cautiously, given the small number of participants who met criteria for this outcome. Accordingly, multivariable analyses predicting 12-month MDD had particularly large confidence intervals. Lastly, because of the relatively low number of MDD cases, we were unable to model additional comparisons such as stratifying depression by racial/ethnic groups, or by finer age intervals.

\section{Conclusion}

Understanding MDD correlates and the nature of intergroup diversity can inform the identification of particularly vulnerable subgroups as well as appropriate treatment approaches.

Even though there has been an increase in the proportion of Americans treated with depression medications, older African Americans and Black Caribbeans report higher rates of depression-related disability, continue to persist in their depression for longer periods of time, and are less likely to receive any type of therapy or guidelineconcordant depression care (Areán \& Unützer, 2003; González et al., 2010a, 2010b). A national response is needed to bring quality depression care and adequate behavioral health care coverage for older US Americans with depression.

\section{Key points}

- Among a national sample of African Americans, Caribbean Blacks, and Whites 55 years of age and older, $11.2 \%$ reported lifetime MDD and $4.1 \%$ reported 12 -month MDD in the last year.

- Similar to previous epidemiological research, non-Hispanic Whites had higher odds of lifetime MDD compared to African Americans.

- Persons with disability are particularly at-risk for both lifetime and 12-month MDD.

- A national response is needed to bring quality depression care and adequate behavioral health care coverage for older US Americans with depression.

\section{Conflict of interest}

None known.

\section{Acknowledgements}

Data collection on which this study is based was supported by the National Institute of Mental Health, National Institutes of Health (NIMH/NIH; U01MH57716), the Office of Behavioral and Social Science Research at the National Institutes of Health (NIH), and the University of Michigan. Preparation of this manuscript was supported by grants from the National Institute of Mental Health grant R21MH080624 (Dr Aranda, PI); the Larson Endowment for Innovative Research-University of Southern California School of Social Work grant 12-2602-4519 (Dr Aranda, PI; Dr Lincoln, Co-I); the National Institute of Mental Health grant R01-MH084963 (Dr Lincoln, PI; Drs Aranda and 
Chatters, Co-I); the National Institute of Mental Health grant R0-MH82807 (Drs Chatters and Taylor, Co-I); and the National Institute on Aging grant P30AG1528 (Dr. Taylor, Co-I). This paper is the result of work supported with resources and the use of facilities at the USC School of Social Work Hamovitch Center for Science in the Human Services

\section{References}

Alegria M, Chatterji P, Wells K, et al. 2008. Disparity in depression treatment among racial and ethnic minority populations in the United States. Psychiatr Serv 59 1264-1272.

Alexopoulos GS. 2005. Depression in the elderly. Lancet 365: 1961-1970.

Areán PA, Unützer J. 2003. Inequities in depression management in low-income, minority, and old-old adults: A matter of access to preferred treatments? J Am Geriatr Soc 51: 1808-1809.

Areán PA, Ayalon L, Hunkeler E, et al. 2005. Improving depression care for older, minority patients in primary care. Med Care 43: 381-390.

Areán PA, Gum AM, Tang L, et al. 2007. Service use and outcomes among elderly persons with low incomes being treated for depression. Psychiatr Serv 58 1057-1064.

Blazer, DG. 2002. Depression in late life, 3rd Edn. Springer Publishers: New York.

Blazer DG. 2003. Depression in late life: Review and commentary. J Gerontol Med Sc 58A: 249-265.

Blazer DG, Kessler RC, McGonagle KA, Swartz MS. 1994. The prevalence and distribution of major depression in a national community sample: The National Comorbidity Survey. Am J Psychiatry 151: 979-986.

Breslau J, Aguilar-Gaxiola S, Kendler KS, et al. 2006. Specifying race-ethnic differences in risk for psychiatric disorder in a US national sample. Psychol Med 36: 57-68.

Brown DR, Feroz A, Gary LE, Milburn NG. 1995. Major depression in a community sample of African Americans. Am J Psychiatry 152: 373-378.

Brown C, Schulberg HC, Madonia MJ. 1996. Clinical presentations of major depression by African Americans and whites in primary medical care practices. $J$ Affec Disord 41: 181-191.

Chapman DP, Perry GS, Strine TW. 2005. Vital link between chronic disease and depressive disorders. Prev Chronic Dis 2: 1-10.

Chatters LM, Bullard KM, Taylor RJ, et al. 2008. Religious participation and DSM-IV disorders among older African Americans: Findings from the National Survey of American Life (NSAL). Am J Geriatr Psychiatry 16: 957-965.

Chatters LM, Taylor RJ, Jackson JS. 1985. Size and composition of the informal helper networks of elderly Blacks. J Gerontol B Psychol Sci Soc Sci 40: 605-614.

Cohen A, Houck PR, Szanto K, et al. 2006. Collaborative care for depression: A cumulative meta-analysis and review of longer-term outcomes. Arch Intern Med 166: $2314-2321$.

Eaton W, Holzer, C, Von Korffet M, et al. 1984. The design of the Epidemiologic Catchment Area Surveys. Arch Gen Psychiatry 41: 942-948.

Ell K. 2006. Depression care for the elderly: Reducing barriers to evidence based practice. Home Health Care Serv Q 25: 115-148.

Ell K, Aranda MP, Xie B, Jiuan P-J, Chou C-P. 2010. Collaborative depression treatment in older and younger adults with physical illness: Pooled analysis of three randomized clinical trials. Am J Geriatric Psychiatry 18: 520-530.

Fiske A, Wetherell JL, Gatz M. 2009. Depression in older adults. Annu Rev Clin Psychol 5: 363-389.

Ford BC, Bullard KM, Taylor RJ, et al. 2007. Lifetime and 12-month prevalence of Diagnostic and Statistical Manual of Mental Disorders, Fourth Edition disorders among older African Americans: Findings from the National Survey of American Life. Am J Geriatr Psychiatry 15: 652-659.

Forthofer MS, Kessler RC, Story AL, Gotlib IH. 1996. The effects of psychiatric disorders on the probability and timing of first marriage. J Health Soc Behav 37: 121-132.

González HM, Vega WA, Williams DR, et al. 2010a. The epidemiology of major depression and ethnicity in the United States. J Psychiatr Res 44: 1043-1051.

González HM, Vega WA, Williams DR, et al. 2010b. Depression care in the United States: Too little for too few. Arch Gen Psychiatry 67: 37-46.

Gum AM, King-Kallimanis B, Kohn R, et al. 2009. Prevalence of mood, anxiety, and substance-abuse disorders for older Americans in the National Comorbidity Survey-Replication. Am J Geriatr Psychiatry 17: 769-781.

Hasin DS, Goodwin RD, Stinson FS, et al. 2005. Epidemiology of major depressive disorder: Results from the National Epidemiologic Survey on Alcoholism and Related Conditions. Arch Gen Psychiatry 62: 1097-1106.

Jackson JS, Knight KM. 2006. Race and self-regulatory health behaviors: The role of the stress response and the HPA axis in physical and mental health disparities.
In Social Structures, Aging, and Self- Regulation in the Elderly, Schaie KW, Cartensen L (eds.). Springer: New York; 189-207.

Jackson JS, Knight KM, Rafferty JA. 2010. Race and unhealthy behaviors: Chronic stress, the HPA axis, and physical and mental health disparities over the life course. Am J Public Health 100: 933-939.

Jackson JS, Torres M, Caldwell CH, et al. 2004. The National Survey of American Life: A study of racial, ethnic and cultural influences on mental disorders and mental health. Int J Meth Psychiat Res 13: 196-207.

Jimenez DE, Alegría M, Chen C-N, et al. 2010. Prevalence of psychiatric illnesses in older ethnic minority adults. J Am Geriatrics Society 58: 256-264.

Katon WJ, Lin E, Russo J, et al. 2003. Increased medical costs of a population-based sample of depressed elderly patients. Arch Gen Psychiatry 60: 897-903.

Kessler RC, Walters EE, Forthofer MS. 1998. The social consequences of psychiatric disorders, III: Probability of marital stability. Am J Psychiatry 155: 1092-1096.

Kessler RC, Berglund P, Demler O, et al. 2003. The epidemiology of major depressive disorder: Results from the National Comorbidity Survey Replication (NCS-R). JAMA 289: 3095-3105.

Kiosses DN, Leon AC, Areán PA. 2011. Psychosocial interventions for late-life major depression. Psychiatr Clin North Am 34: 275-510.

Levin JS, Taylor RJ, Chatters LM. 1994. Race and gender differences in religiosity among older adults: Findings from four national surveys. J Gerontology Soc Sci 49: S137-S145.

Liao Y, McGee DL, et al. 1999. Black-white differences in disability and morbidity in the last years of life. Am J Epidemiol 149: 1097-1103.

Lincoln KD, Taylor RJ, Chae DH, Chatters LM. 2010. Demographic correlates of psychological well-being and distress among older African Americans and Caribbean Black adults. Best Practices in Mental Health 6: 103-126.

Mathers CD, Loncar D. 2006. Projections of global mortality and burden of disease from 2002 to 2030. PLoS Med 3: e442. doi:10.1371/journal.pmed.0030442

McKenna MT, Michaud CM, Murray CJ, Marks JS. 2005. Assessing the burden of disease in the United States using disability-adjusted life years. Am J Prev Med 28: $415-423$

Mezuk B, Rafferty JA, Kershaw KN, et al. 2010. Reconsidering the role of social disadvantage in physical and mental health: Stressful life Events, health behaviors, race, and depression. Am J Epidemiol 172: 1238-1249.

Mitchell A, Subramaniam H. 2005. Prognosis of depression in old age compared to middle age: A systematic review of comparative studies. Am J Psychiatry 162: $1588-1601$.

Nutting PA, Rost K, Smith J, Werner JJ, Elliot C. 2000. Competing demands from physical problems: Effect on initiating and completing depression care over 6 months. Arch of Family Med 9: 1059-1064.

Papakostas GI, Peterson T, Mahal Y, et al. 2004. Quality of life assessments in major depressive disorder: A review of the literature. Gen Hosp Psychiatry 26: 7-13.

Piccinelli M, Wilkinson G. 2000. Gender differences in depression. Br J Psychiatry 177: 486-492.

Robins LN. 1991. Psychiatric disorders in America. The Free Press: New York. Am J Public Health 79: 727-730.

Rost KM, Nutting P, Smith J, et al. 2000. The role of competing demands in the treatment provided primary care patients with major depression. Arch Family Med 9: $150-154$.

Salzman C, Schneider LS, Alexopoulos G. 2000. Pharmacological treatment of depression in late life (revised chapter). In Pharmacology: The fourth generation of progress, Bloom FE, Kupfer DJ (eds.). Robin Press: New York. Retrieved on August 4, 2011 at: http://www.acnp.org/publications/psycho4generation.aspx

Scott KM, Von Korff M, Alonso J, et al. 2008. Age patterns in the prevalence of DSMIV depressive/anxiety disorders with and without physical co-morbidity. Psychol Med 38: 1659-1669.

Simon G, Vonkorff M, Ustun Bedirhan T, et al. 1995. Is the lifetime of depression actually decreasing? J Clin Epidemiol 49: 1109-1118.

Takeuchi DT, Chung C-Y, Lin K-M, et al. 1998. Lifetime and twelve-month prevalence rates of major depressive episodes and dysthymia among Chinese Americans in Los Angeles. Am J Psychiatry 155: 1407-1414.

Taylor RJ, Chatters LM, Jackson JS. 2007. Religious and spiritual involvement among older African Americans, Black Caribbeans and Whites: Findings from the National Survey of American Life. Journal of Gerontology: Social Sciences 62B: S238-S250.

Thornton MC, Chatters LM, Taylor RJ, Allen WR. 1990. Socio-demographic and environmental influences on racial socialization by Black parents. Child Dev 61: 401-409.

Weissman MM, Bruce LM, Leaf PJ, et al. 1991. Psychiatric disorders in America: The Epidemiologic Catchment Area Study. The Free Press: New York.

Williams DR, González HM, Neighbors H, et al. 2007. Prevalence and distribution of major depressive disorder in African Americans, Caribbean Blacks, and nonHispanic whites: Results from the National Survey of American Life. Arch Gen Psychiatry 64: 305-315.

Williams DR, Takeuchi DT, Adair RK. 1992. Marital status and psychiatric disorders among Blacks and Whites. J Health Soc Beh 33: 140-157.

Woodward AT, Taylor RJ, Bullard KM, et al. 2008. The use of professional services and informal support among Black Americans with a mental disorder. Psychiatric Serv 59: 1292-1298. 